Australian Journal of

Educational Technology

\title{
Learning and teaching in virtual worlds: Implications of virtual reality for education
}

\author{
Paul Moore
}

University of Wollongong

Though Virtual Reality is at a relatively rudimentary stage of development, many argue it is destined to influence both educational theory and practice. Active research into the educational implications of VR for education is underway and mainly focuses on the phenomena related to the immersion of individuals in a simulated environment. This paper surveys the research into VR and focuses on the implications of immersive virtual worlds for learning and teaching.

Louis XIV thanked Rimmer for the Ray Ban sunglasses and the Sony Walkman and bade him farewell. Rimmer gingerly made his way over to the time copter, followed by Kennedy, Van Gogh, Einstein and Caesar. Elvis crammed a steak into his mouth, stuffed a second into his pocket, grabbed four bread rolls and followed them.

The game is called Better Than Life and very few can escape its thrall: very few can give up their own, personally sculpted fantasy. (Grant Naylor, Red Dwarf Omnibus, 1992).

This paper offers an overview of virtual reality (VR) as it relates to education and, to an extent, its place in society. It first surveys definitions of the various phenomena which may constitute VR and the physical and conceptual attributes which separate VR from interactive multimedia (IMM), making it more a learning environment rather than an educational tool. The paper then examines the implications of VR for educational theory, methodology and practice, focussing on case studies of VR research in education and society. 


\section{What is virtual reality?}

The early stages of development of any new technology or theory are often confounded by disagreement over what that technology actually involves. Any definition of virtual reality is further confounded by claims that it is not a technology, but a set of emerging phenomena which are enabled by another set of rapidly developing technologies and informed by yet another complex set of sociocultural influences. VR is a set of rapidly developing computer generated phenomena in search of a definition. Popular representations of VR (in advertising and movies) are unrelated to today's VR capabilities. However, the technology's rudimentary state seems to be the only barrier to the fulfilment of the science fiction fantasies which are provided by the current press. A survey of the literature on VR does, however, reveal some recurring themes.

Virtual reality falls into three major categories: text-based, desktop and sensory-immersive VR. Text-based networked VR involves real-time environments described textually on the Internet where people interact by typing commands and "speak" by typing messages on their computer keyboards. This has been valuable in distance education (Psotka, 1994). Desktop VR is an extension of interactive multimedia involving three dimensional images and adds to the experience of interactive multimedia without being considered immersive. Sensory-immersive VR, the focus of this paper, involves a mixture of hardware, software and concepts which allow the user to interact with and in a three dimensional computer generated "world" (Loeffler \& Anderson, 1994).

The specific hardware which currently enables immersive VR includes head mounted displays (HMD or 'eyephones') which provide 3D vision of 200 degrees horizontally and 120 degrees vertically (Wine, 1993); datagloves or datasuits which allow the user to interact with the environment by tracking the users motion and giving tactile reinforcement to the visual stimuli in the simulated world and wands or other devices which allow the user to manipulate objects in the virtual world.

The major software required for VR includes high resolution image generators which allow real time rendering so the virtual world is updated as the user acts upon it; and software which allows localised stereo sound and in some cases smell and voice recognition (Psotka, 1994).

VR involves a number of interrelated defining and variable concepts. Thurman and Mattoon (1994) summarise these as integration, interface and verity. Integration of the user in the virtual environment is claimed to be an essential part of VR. The concept of interface for VR is such that the interface disappears, allowing the user to interact directly with the virtual world. Verity is defined as whether or not the virtual world is "true to life", representing either real world or abstract concepts and relationships. This 
concept is entirely variable and is one of the most important aspects of VR in education.

As well as these, Hedberg and Alexander (1994) include sensory and psychological immersion and active learner participation as defining educational factors of VR. Bricken (1990, quoted in Winn, 1994) describes the result of VR's mixture of hardware, software and concepts as a phenomenon known as "cognitive presence", involving a "conviction that the virtual world is a valid, though different, form of reality" (Winn, 1994). This phenomenon has been likened to the "suspension of disbelief" we experience whilst watching a play or movie, but appears to involve less effort on the part of the audience or user, with far more convincing effects.

\section{How does VR differ from other forms of interactive multimedia?}

Common conceptualisations of VR in relation to interactive multimedia (IMM) portray a set of interrelated continua with VR at one end of the spectrum and IMM at the other. Hedberg \& Alexander (1994) interrupt the continuum of interface midway to show that the point where interface disappears into the context is a quality which is unattainable in IMM; that this is where the complete paradigm shift exists between VR and IMM:

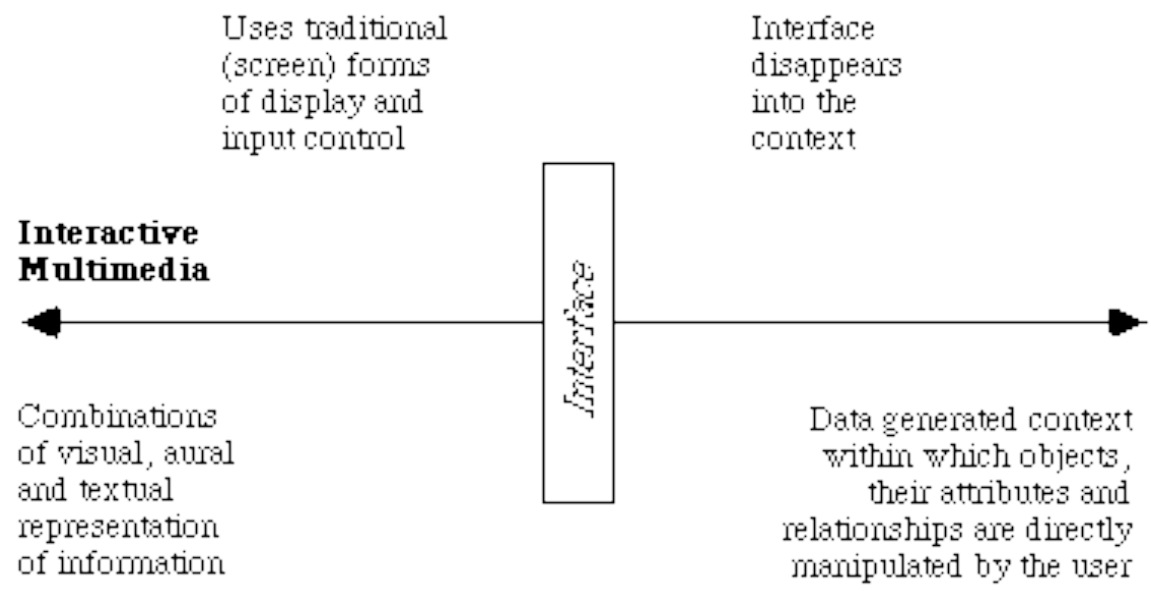

Figure 1: The relationship of interface between VR and IMM

(Hedberg \& Alexander, 1994).

Thurman and Mattoon (1994) provide a thought provoking 3D classification of VR using their aforementioned concepts of integration, verity and interface, which allows comparisons with other kinds of IMM: 


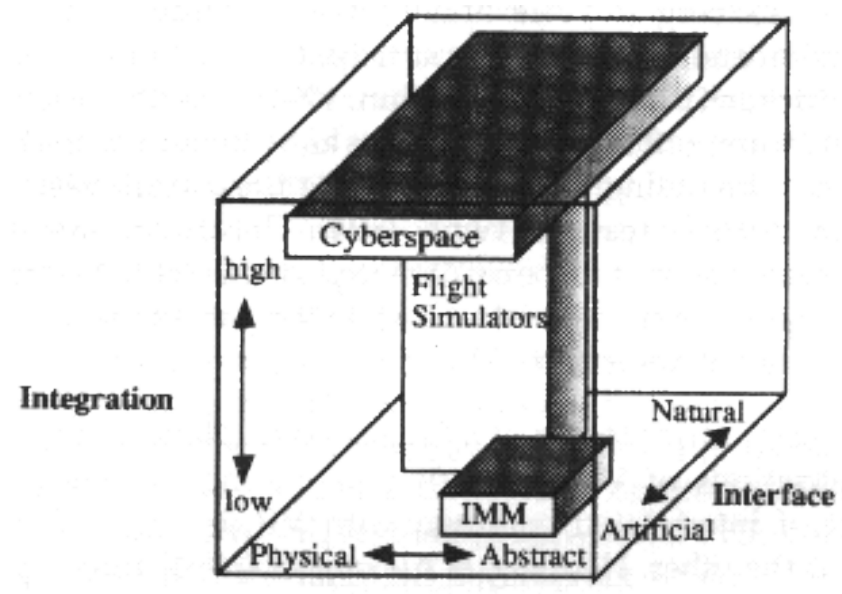

Verity

Figure 2: An interpretation of Thurman \& Matoon's 3D Virtual Reality Classification.

Here rises the problem of definition of concepts for the rudimentary technology and concepts of VR. Thurman \& Mattoon's high scale of integration of the user into the environment equates to immersion. Their inclusion of the term cyberspace actually refers to the virtual world in immersive VR. Cyberspace elsewhere and more commonly refers to the "unified conceptualisation of space spanning the entire Internet" (Pesce et al., 1995) and will only be treated in this paper in relation to distributed forms of VR. Other concepts which are ambiguously defined in the literature are avatars and virtual objects or institutions. Avatars, derived from an incarnation of a Hindu deity, have been defined as the computer generated puppet which represents the user in VR, as well as the guide which may be included in the virtual world to provide the user assistance in navigation or otherwise. Virtual reality has taken the word virtual from common usage and given it connotations of VR, especially when related to information technology. The problem is that it is ambiguously used to represent distributed interactive technologies which have little to do with VR. The Virtual Classroom (trade mark of the New Jersey Institute of Technology) (Turoff, 1995), Virtual Campus Environment (Paquette et al., 1994), Virtual English Language Center and Virtual Textbooks are all distributed IMM or Hypertext projects and not VR. The creators of these products use the word "virtual" rather loosely in the sense that they offer some of the learning possibilities found in real environments. The Networked Virtual Art Museum (Loeffler, 1993) is an immersive VR project where users are placed in a computer generated "world" of Art. 


\section{The state of the art}

Most discussions of VR are actually about its future applications. Penny (1994) notes that "virtually all commentators discuss it as if it were a fully realised technology". Focusing on the technological side of VR, some note that it could be up to 25 years before complex $3 \mathrm{D}$ virtual databases are easily accessible for educational purposes (see Traub, 1994). Currently, as Loeffler and Anderson (1994) describe, graphical displays in VR are achieved by wrapping two dimensional images around a 3D "frame". The combined problems of slower rendering than the 24 frame per second rate required for a convincing illusion along with the time taken for the system to respond to the user's movements restrict the effectiveness of VR (Loeffler \& Anderson, 1994). Simulation sickness as Psotka (1994) notes, is a result of inaccurate information provided to the user and can range from mild eye strain to nausea. Psotka adds that the low resolution and cartoon like shapes which are evident in current VR are a result of the fact that the graphical frames are created by using only a few thousand polygons per second, and that nearly a billion polygons may be required for near realism.

Although VR technologies are far from fully realised, the concepts and culture behind VR are preparing in anticipation of the time when VR will be able to provide accurate graphical rendering and tracking. There seems to be no doubt that imminent technologies will solve the current problems of VR, so theorists, practitioners and popular culture are wasting no time in testing the virtual waters with the current dynamic technologies available.

In addition, although, as stated earlier, the popular view created by the media is currently science fiction, science fiction may be the best precursor to future fact. As one of the pioneers of VR and inventor of one of the first HMDs, Ivan Sutherland, stated in his 1965 paper:

The Ultimate Display would, of course, be a room within which the computer can control the existence of matter. A chair in such a room would be good enough to sit in. Handcuffs in such a room would be confining, and a bullet displayed in such a room would be fatal. With appropriate programming, such a display could literally be the Wonderland into which Alice walked. (quoted from VR: An Internet Resource Archive, 1995).

Though this, along with representations of VR in the popular media, especially in American films, is currently in the realm of scientific fantasy, to a certain extent, virtual worlds are and will be limited only by the imagination of their creators, whether or not they conform to physical laws in the real world. 


\section{VR and the development of educational theory and methodology}

Development of models of learning have historically coincided with technological developments, from Behaviourist theory's focus on mechanical control to Cognitive theory's focus on the mind as computer paradigm. Constructivism, though perhaps not directly influenced by the development of VR, seems complementary to it in that it represents a detachment from the definition of the mind as computer. Constructivism, as noted by Jonassen (1994) proposes that:

\section{learners construct their own reality, or at least interpret it based on their perceptions of experiences, so an individual's knowledge is a function of one's prior experiences.}

Current usage of the computer in communications via the Internet, for example, has meant that the computer is being redefined as an interface into a more and more human environment, rather than simply an advanced storage and retrieval mechanism. VR takes this further again by removing the interface and placing the user inside the computer generated, but also human generated environment. The user interacts with and acts directly upon the virtual environment and influences the variables in the environment. As information technology further approximates reality, the concept of reality and our place in it is challenged, providing us with the need to redefine ideas according to the new cultural perspectives provided by these developments.

Corresponding to the above developments of educational theory and its correlation with technological developments, Winn (1993) purports that, in instructional design at least, there have been four generations of development.

From behaviourist theory developed traditional drill and practice tutorial instructional design which focuses on imparting objective knowledge or content to the learner. The second and third generations have been informed by cognitive theory's focus on the processes involved in assimilating and encoding information. The second stage of instructional design focuses on the designer and strategies he or she may use to reduce the cognitive load on students and thereby facilitate instruction. The third generation focuses on the relationship between the user and the information presented. This stage would include intelligent tutors which attempt to adapt to individual learning styles by responding to the user's interaction with the program. The fourth generation focuses on the Constructivist premise that knowledge is constructed by the learner, "not delivered by the courseware". The use of the word generation by Winn suggests that Constructivism has superseded all other forms of educational theory. Jonassen (1994) differs, stating that objectivist models and constructivist models are both useful in different contexts. 
In this regard, both cognitive and constructivist varieties of research are focusing on the value of concepts such as first person experience via cognitive presence in a virtual world. In addition, the cognitive objectivist paradigm is focussing on $3 \mathrm{D}$ perception, or spatial cognition, and the transfer of information learned in a virtual world to other environments, while the constructivist research has a further focus on the ways in which knowledge is created and negotiated in virtual environments and the influence of social learning in multi-user environments.

With regard to first person experience through immersion, it has been argued that traditional education requires learners to learn complex symbols before concentrating on concepts which are imparted indirectly via educators. Thus many learners may fail because they have problems with the symbolic nature of education, rather than the concepts being communicated. It has been argued that non-symbolic interaction, where an individual experiences the world without deliberate reflection and directly, is a possible powerful tool in VR for education, where learners may grapple directly with the concepts (Winn, 1994). Penny (1994) refutes this, stating that culturally laden pictorial representations in VR constitute symbolism. However, VR does seem to offer the possibility of more direct and varied learning environments.

Spatial cognition has been identified as an important part of childhood development where children learn to make use of contextual clues in gathering knowledge of the world around them (Osberg, 1993). Visualisation, the process of internalising relationships in the real world in a way that is defined and understood by the individual, is an integral part of this problem solving. Osberg (1993) states that VR provides a unique opportunity to assist the user in creating these associations by providing guided visualisation. Osberg's experiment, Puzzle World, is mentioned in the following case studies.

Lave (1981, cited in Hedberg and Alexander, 1994) focuses on the social nature of learning and that learning seems to occur more readily among one's peers. Vygotsky (1978 quoted in Psotka, 1994) stated that experience is both social and perceptual. Multiple user VR environments, including those connected to remote sites via the Internet, then may have the ability to engage learners socially and perceptually.

\section{Implications of virtual reality for educational practice}

Educational applications of immersive VR have partially grown out of its development for US Defense Force applications and research simulations and more recently distributed text-based VR has had influences on research in schools.

The US Defense Force has used VR to train people in combat techniques as well as navigation of various types of vehicle, from aircraft to aircraft 
carriers (Psotka, 1994). Repairs to the Hubble Space Telescope were simulated in VR before the actual repairs were done to familiarise the technicians with the dangerous conditions they would experience. Another similar application is in medical education (Traub, 1994), where budding surgeons can practise their techniques. The effectiveness of these real world applications has been researched and it has been shown, albeit inconclusively that people can learn to perform tasks in a virtual world and this knowledge can be accurately transferred to the real world. The skills tested have been console operating skills and large scale spatial navigation (see Psotka, 1994). These applications of VR may be described as the more behavioural applications of VR, where conditions in the real world are simulated for reasons of safety, expense or distance.

Other applications of VR for education which are more suited to the cognitive paradigm result from the ability to manipulate or suspend some of the laws of nature to highlight others. For example, an object can be made infinitely smaller or larger to focus on either microscopic detail or macroscopic relationships (Wine, 1994). By manipulating the sensory input the user receives it is also possible to simulate and highlight factors such as sound waves or UV light using colour.

This in fact is where the cognitive and constructivist paradigms meet. It is possible in a virtual world to build instructional design into aspects or objects with which the learner must interact (Traub, 1994). Therefore the user may actually experience knowledge which the virtual world is designed to impart. The combination of senses and experience facilitates perception as well as allows the user to define his or her construction of that knowledge through experience.

A final way of creating learning experience and transference is to allow users to construct and experience their own abstract worlds, giving them first hand experience in the transfer of two dimensional knowledge into three dimensional knowledge.

In other words, the value of VR for education lies within its ability to provide immersion of the user in either realistic or novel and abstract environments. The immersion allows the user to experience, interact with and discover digital knowledge first hand while the manipulation of the verity of the virtual world allows the user to make visual or kinesthetic relationships to help understanding of the real world or concepts related to it. Finally it may bring information to the user which is not normally available in traditional educational settings.

\section{Case studies in educational virtual reality research}

Research into the applications of VR for learning are being carried out in the form of short term and longitudinal case studies. Development of virtual worlds is being carried out by educationalists for use in schools, by 
students for research purposes and on the Internet for the purposes of research and distance learning.

The University of Washington's Human Interface Technology Lab (HITL) is perhaps most involved in experimenting with students in real educational settings using current VR technology. It introduces 10-15 year old students to VR during their summer camps. Osberg's (1994) Puzzle World project aimed to improve spatial concepts in children with spatial processing problems by having them use these concepts intensively in designing a VR environment. This was done by having the students plan and create 3D puzzles which would be integrated into Puzzle World, where they would be able to interact with their own and others' puzzles. The central hypothesis was that by teaching the students to think in $3 \mathrm{D}$, using visualisation techniques their spatial cognition would be enhanced having a positive effect in other areas of the children's lives. The program lasted for one week and students were pre- and post-tested for among other variables spatial cognition, visualisation and creative problem solving.

The students spent four days learning about the software and creating their puzzles. The whole group improved significantly in the short time on the post-tests, but the findings were inconclusive as to which aspect of the week's work was responsible for the improvements. In conclusion, Osberg states that there may be much to be gained from reintegrating a visual component back into the classroom.

Bricken and Byrne (1992) allowed Seven groups of students seven weeks to create their own virtual worlds. The students' worlds were dynamic and interesting and the collaboration was highly cooperative. The themes of the worlds ranged from Cloudlands to a Moon Colony. The students who created cloudlands agreed to disagree on topics so each created his or her own environment on a cloud. These environments ranged from an elaborate house to a sea world. The moon colony project was a more collaborative rendition of the moon in the future, complete with monorail, mountains, futuristic buildings and space craft. The students experienced each others worlds at the end of the seven weeks.

In using the worlds the students on the whole had no problems navigating, though one experienced severe disorientation leading to questions about individual reactions to the virtual environment. Interacting with objects was considerably more difficult, but Bricken and Byrne note that this may be due to the creator's lack of experience. Behaviour such as bending down and reaching out were common, with Bricken and Byrne noting an avenue for research into the implications of VR for kinesthetic learners. Bricken and Byrne found VR in this study to be a significantly compelling creative learning environment.

Another VR project is the US WEST VR Roving Vehicle project, which was created in 1994. The vehicle was funded by the US WEST Foundation and 
is run by HITL. It aims to expose students and teachers to virtual worlds created by HITL staff and by the students themselves. The aim of this program is informed by constructivist theory: to give students who may not perform well in the traditional abstract educational environment first hand experiences of concepts and procedures. The focus of the research is on designing and using VR. This focus is in part a result of limited resources. One of the virtual worlds produced by HITL staff is Tree World.

The goal of Tree World is for the user to identify parts of a tree and determine what items from the environment the tree needs to be healthy. The graphics and activities in this world are rudimentary and the interactivity involves such activities as sliding a cloud out of the way to give the tree sunlight. The current restrictions of this project will possibly be overcome when international projects are underway via the Internet.

A final application of VR is Distributed VR via the Internet. Much more funding and international collaboration seems to be involved in this type of activity and it is through this international collaboration that the educational applications of VR may be realised. Virtual Reality Markup Language (VRML) is fast being developed for platform independent VR (and projects such as the Networked Virtual Art Museum were demonstrated as early as 1992 (Loeffler, 1994). One of the great possibilities here is that users will be able to create their own online worlds or contribute to those created by others. This is a concept which arose out of the Text-based virtual reality MUDs (Multiple User Dungeons (or Dimensions)) and MOOs (MUD Object-Oriented) which are an integral and dynamic part of the Internet as it stands today.

The above case studies reveal the rudimentary state of commercial VR systems and to a certain extent the resultant difficulties in applying this technology to education. The more successful case studies appear to involve collaborative and relatively self-defined creative projects. Instructionally then, a template which supports creation of a world or addition of areas to a world with predefined "laws" which highlight certain instructional features is one method of creating educational experience worthy of research. Although VR systems are "awkward, limited in capability and marginally reliable to use" (Bricken \& Byrne, 1992), those who are using them are finding more and more applications and are gathering valuable research findings to support further exploration of the aforementioned issues.

\section{Conclusion}

Virtual Reality is a rudimentary technologically based set of phenomena with limited application to education at present. However, the issues raised by the existence of VR have led to some redefining of educational theory, methodology and technology, and hearty discussion of how VR could be used in education if the technology could match the definitions of VR in popular myth. 
Current theory and methodology therefore is based on what will most likely be future fact, when the technologies associated with VR are able to do what they are being designed to do: to develop accurately rendered worlds which can successfully create a complex illusion of cognitive presence. Once this is possible on a day to day basis, the concepts of learning through guided or self guided experience in virtual worlds of variable verity may be attained.

\section{Bibliography}

Bricken, M. \& Byrne, C. (1992). Summer students in virtual reality: A pilot study on educational applications of VR technology.

http: / / www.hitl.washington.edu / publications / r-92-1/

Byrne, C., Holland, C., Moffit, D., Hodas, S. \& Furness, T. (1994). Virtual reality and 'at risk' students.

http:/ / www.hitl.washington.edu/ publications / r-94-5/

di Sessa, A. A. (1987). Artificial worlds and real experience. In Lawler, R. W. \& Yazdani, M. (eds), Artificial Intelligence and Education. Ablex Publishing Corporation. New Jersey.

Harmon, S. W. \& Kenney, P. J. (1994). Virtual reality training environments: Contexts and concerns. Educational Media International, 31(4), 228-237.

Hedberg, J. \& Alexander, S. (1994). Virtual reality in education: Defining researchable issues. Educational Media International, 31(4), 214-220.

Jonassen, D. H. (1994). Thinking technology: Toward a constructivist design model. Educational Technology, April, 34(4), 34-37.

Lawler, R. W. (1987). Learning environments: Now, then and some day. In Lawler, R.W. \& Yazdani, M. (eds), Artificial Intelligence and Education. p1-25. Ablex Publishing Corporation. New Jersey.

Loeffler, C. E. (1993). Distributed virtual reality: Applications for education, entertainment and industry. Telektronikk, 4. http:/ / www.nta.no/telektronikk/tema/nr4_93.html

Loeffler, C. E. \& Anderson, T. (eds) (1994). The Virtual Reality Casebook. Van Nostrand Reinhold. New York.

OdeGard, O. (1994). To live in a virtual polis. In Loeffler, C. E. \& Anderson, T. (eds), The Virtual Reality Casebook. Van Nostrand Reinhold. New York.

Osberg, K. M. (1993). Puzzle World: A spatial cognition learning environment. http:/ / www.hitl.washington.edu/publications /

Osberg, K. M. (1993). Virtual reality and education: A look at both sides of the sword. http: / / www.hitl.washington.edu / publications / r-93-7 /

Osberg, K. M. (1994). Rethinking educational technology: A postmodern view. http:/ / www.hitl.washington.edu/publications / r-944 /index.html

Palmer, D. (1994). Look, no gloves! Educational Computing and Technology, January, 1994, 12-15.

Pantiledes, V. (1995). Personal correspondence via email, October 10, 1995.

Penny, S. (1994). Virtual reality as the completion of the enlightenment. In 
Loeffler, C. E. \& Anderson, T. (eds), The Virtual Reality Casebook. Van Nostrand Reinhold. New York.

Pesce, M., Kennard, P. \& Parisi, A. (1995). Cyberspace.

http:/ / vrml.wired.com/ concepts /

Psotka, J. (1994). Immersive tutoring systems: Virtual reality and education and training. http:/ / alex.immersion.army.mil/

Raggett, D. (1995). Extending WWW to support platform independent virtual reality. Hewlett Packard Laboratories.

http: / / vrml.wired.com/ concepts /

Rose, Howard (1995). Assessing learning in virtual reality: Towards developing a paradigm.

http: / / www.hitl.washington.edu/publications / r-95-1/

Siegel, M. A. \& Sousa, G. A. (1994). Inventing the virtual textbook: Changing the nature of schooling. Educational Technology, October, 1994, 49-54.

Thurman, R. A. \& Mattoon, J. S. (1994). Virtual reality: toward fundamental improvements in simulation-based training. Educational Technology, October, 1994, 56-64.

Traub, D. (1994). The promise of virtual reality for learning. In Loeffler, C. E. \& Anderson, T. (eds), The Virtual Reality Casebook. Van Nostrand Reinhold. New York.

Turoff, M. (1995). Designing a virtual classroom. 1995 International Conference on Computer Assisted Instruction. http:/ / it.njit.edu/department/cccc/vc/papers/

Winn, W. (1993). A conceptual basis for educational applications of virtual reality. HITL Laboratory. http:/ / www.hitl.washington.edu / publications / r-93-9/

Yaverbaum G. (1994). Multimedia paradox: Where do we go from here? Educational Multimedia and Hypermedia, 1995 Proceedings, Austria. p701-705.

Please cite as: Moore, P. (1995). Learning and teaching in virtual worlds: Implications of virtual reality for education. Australian Journal of Educational Technology, 11(2), 91-102.

http: / / www.ascilite.org.au/ajet/ajet11/moore.html 